\title{
Comparison of the Cost of Co-Production of Power and Desalinated Water from Different Power Cycles
}

\author{
P. Asiedu-Boateng ${ }^{1,2}$, B. J. B. Nyarko² ${ }^{2}$ S. Yamoah $^{1}$, F. Ameyaw ${ }^{1}$, K. Tuffour-Acheampong ${ }^{1}$ \\ ${ }^{1}$ National Nuclear Research Institute, Ghana Atomic Energy Commission, Accra, Ghana \\ ${ }^{2}$ Graduate School of Nuclear \& Allied Sciences, University of Ghana, Accra, Ghana \\ Email: pierob79@yahoo.co.uk
}

Received August 13, 2012; revised September 17, 2012; accepted September 30, 2012

\begin{abstract}
The worldwide demand for portable water is steadily growing due to population, industrial and agricultural growth, the result is water shortages that are already reaching serious proportions in many parts of the world. This is particularly true in Ghana where there is an increasing reliance on bottled water due to shortage of safe, fresh drinking water. Nuclear and conventional co-production of electricity and portable water has been identified as key solution to the perennial water shortages in coastal towns in Ghana. A reliable desalination cost date catering for site-specific condition in Ghana is required for policy makers, planners, consultants, process engineers, plant suppliers and researchers. This present paper is aims comparing the cost of co-production of power and portable water using reverse osmosis (RO) plant coupled with both nuclear and fossil power plant operating under different cycles using the desalination economic evaluation programme (DEEP4.0) developed by the international atomic energy agency (IAEA). The study concentrates on conditions of seawater in Accra, Ghana. Results show that co-production nuclear power plant operating on steam cycle can be the most economic among a number of power-water production options.
\end{abstract}

Keywords: Cogeneration; Power; Desalination; Economic Comparison

\section{Introduction}

In many regions of the world the supply of renewable water resources is inadequate to meet current demand. The worldwide demand for portable water is steadily growing due to population, industrial and agricultural growth, the result is water shortages that are already reaching serious proportions in many parts of the world. This is particularly true in Ghana where there is an increasing reliance on bottled water due to shortage of safe, fresh drinking water. To mitigate the stress being placed on water resources, additional fresh water production capability must be developed. Ghana has long a coastline; therefore seawater desalination is a good alternative.

The cost of desalination is decreasing in recent times due to improvement in desalination technologies and desalination is now able to successfully compete with convectional water resources for portable water supply. However the cost of desalination is site-specific mostly based on the quality and temperature of feed water available at the selected site. Moreover the seawater desalination is an energy intensive process and the source of energy as well as the power plant cycle adopted contributes significantly to the overall cost of desalinated water [1]. Nuclear and conventional co-production of electricity and portable water has been identified as key solution to the perennial water shortages in coastal towns in Ghana. In cogeneration plants, the primary product has usually been electricity production, but some of the generated energy can additionally drive a desalination unit for producing fresh water from sea as a by-product.

Plans for setting up of power-desalination plants must include selecting suitable sites, and studying the common difficulties in carrying out economic evaluations. Comparisons should be made between the economics of nuclear power and convectional power to guide the selection of a set of economic parameters for a "fair" comparison. As a matter of fact nuclear power plants have high capital cost, relatively long construction times, and relatively low fuel cycle costs whereas convectional fuelled power plants typically have low capital cost, shorter construction times and higher fuel cycle costs. The specific values of these competing factors may change the results towards one of these power options. Also complex calculations must be made to determine the power and water production costs resulting from each technical combination in order to fine-tune the economical optimization for cogeneration plants. Again the type of power cycle adopted such as steam, gas and or combined can have an immense contribution to the cost of both the 
product and by-product of cogeneration [2].

Reverse osmosis is one of the most cost effective technologies which can utilise waste heat from a power plant to enhance the economics of the process. A feasibility study was carried out in 2011 towards the establishment of 60,000 cubic metres per day at Nunqua in Accra, Ghana [3]. Cost estimation for any combination of power source and cycle coupled to reverse osmosis plant for any particular site is necessary steps towards the selection of the most economic combination taking into account the prevailing conditions of seawater in Nunqua district. A reliable desalination cost date catering for site-specific condition in Ghana is required for policy makers, planners, consultants, process engineers, plant suppliers and researchers. Policy makers, planners and consultants need the data conducting feasibility studies for selection of appropriate technologies, process engineers to optimise process configuration and equipment sizing for minimizing the cost of production and researchers for developing new technologies and improving existing ones.

Generation of cost date can be achieved using modern computer codes. Some studies have been carried out in other parts of the world such as south Europe, North Africa and Arabian Sea where fresh water shortage is a serious problem [2]. Nisan and Dadour [4] presented detailed analyses of power and water costs for several nuclear reactors operating in a cogeneration mode and coupled to the two main desalination processes (MED) and (RO) in Tunisia. Discussion on the costs dependent parameters in the case of an RO desalination system coupled to a combined cycle cogeneration plant for specific conditions in Morocco [5]. Other workers [6-10] focused on specific cycles such as Rankine and gas cycles with site specific conditions. The aim of the present paper is to make a comparison of the cost of co-production of power and portable water from RO plant coupled with both nuclear and fossil power plant operating under different cycles. Desalination economic evaluation programme (DEEP4.0) developed by the international atomic energy agency (IAEA) will be applied in the analysis.

\section{Theory}

DEEP uses the power credit method for desalination cost evaluation to treat the rather complex problem of two products, namely water and electricity. An equivalent net electricity generating cost $\left(C_{E}\right)$ is set equal to the saleable electricity cost $\left(C_{O}\right)$ of an imaginary single purpose power plant, representing the dual-purpose plant, divided by the generating net energy $\left(E_{A}\right)$.

$$
C_{E}=\frac{C_{O}}{E_{A}}
$$

The amounts of desalted water $(W)$ and the net saleable power $E_{2}$, produced by the plant at a total expense $C_{2}$, are then calculated. The desalted water is then credited by the net saleable power cost so that the water cost is given by (2)

$$
C_{W}=\frac{\left(C_{2}-E_{2} \times C_{E}\right)}{W}
$$

DEEP evaluates the life time levelised unit cost of both power and water production. The methodology adopted in levelised unit cost evaluation is found in [11].

\section{Site Specifications}

The geographical area chosen has its own characteristics which mainly control the water cost and power cost. These specifications include cooling water temperature and feed water quality in terms of total dissolved salts (TDS); and human resources specifications [2,3]. In this analysis, specific site conditions in Nunqua Suburb, in Accra were considered. The analysis is deemed essential in Ghana as desalination has been identified as a good option to solve the perennial water shortages. The range of sea temperature and salinity also personal costs are presented. Table 1 illustrates the input data for Nunqua Suberb in Accra.

\section{DEEP Simulations}

Cost calculations in deep are done for both power and water plants and are case-specific. Capital costs as well as fuel, operation and maintenance and other costs are taken into consideration. Water capacity scaling can also be specified. DEEP uses the power credit method to estimate the value of steam in co-generation system. The DEEP model allows different power sources and cycles to be coupled with reverse osmosis desalination plants with operating on varying technologies. Each coupling configuration and the results of the simulations have been presented following sections.

\subsection{Coupling RO with Nuclear Power Plant}

Nuclear desalination is an option in Ghana. The 60,000 $\mathrm{m}^{3} /$ day RO plant was coupled with nuclear power plant with steam cycle (SC), gas cycle (GC) and Combined cycle (CC) and simulations performed. Both water and power costs were obtained with interest rate and discount rate both at $5 \%$ and fuel escalation at $3 \%$.

Table 1. Input geographical area specifications [2,3].

\begin{tabular}{cccc}
\hline \multicolumn{2}{c}{ Seawater Condition } & \multicolumn{2}{c}{ Personnel Costs } \\
\hline Temp. & TDS & Mgnt. & Labour \\
${ }^{\circ} \mathrm{C}$ & $\mathrm{ppm}$ & $\$ / \mathrm{yr}$ & $\$ / \mathrm{yr}$ \\
24 & 35,000 & 600,000 & 300,000 \\
\hline
\end{tabular}




\subsection{Coupling RO Plant with Coal Power Plant}

Heat or electricity to be used for desalination purposes may be produced by burning conventional fuels. Several power plant options are applicable and some of them are presently used to produce the majority of desalted water in the world. In this study, two conventional power production plants have been taken into consideration. The three power cycles considered included two gas cycle and combined cycle, and steam cycle electric production plants. Discount rate and interest rate of 5\% and fuel escalation at $3 \%$ were used.

\subsection{Coupling RO Plant with Oil/Gas Power Plant}

Heat or electricity to be used for desalination purposes may be produced by burning conventional fuels. This is a possibility in Ghana since there are Oil/Gas power plants operating in Ghana. Several power plant options are applicable and some of them are presently used to produce the majority of desalted water in the world. In this study, two conventional power production plants have been taken into consideration. The three power cycles considered included two gas cycle and combined cycle, and steam cycle electric production plants. Discount rate and interest rate of $5 \%$ and fuel escalation at $3 \%$ were used.

\section{Sensitivity Analyses}

Sensitivity analyses were also carried out with variations in several important parameters that could potentially have a significant influence on the final water and power cost. The parameters that were varied for these sensitivity analyses include discount rate, interest rate, fuel escalation, power plant availability. These calculations were carried out to permit an evaluation and understanding of possible trends in the cost of water production as potentially significant factors changed, and to help understand which of the many input parameters required for a desalination economic evaluation are in fact important to the cost of water production. The sensitivity analyses were carried out for three coupling configurations in Section 3 above.

\section{Results and Discussion}

\section{Water Cost.}

The cost of water production using various power plant cycle and desalination configuration is shown in Figure 1.

As shown in Figure 1, water desalination cost from an RO plant coupled with nuclear power plant operating on the steam cycle (NSC) is about 35\% lower than the same desalination plant coupled with Oil/Gas power plant operating on the steam cycle (OSC). The (RO + NSC) is 6\% lower than the RO plant coupled with coal fired power plant operating on steam cycle (CSC). The cost of water production from coal fired power plant operating on the steam cycle is about 31\% lower than an oil fired power plant when coupled with the RO plant.

Comparison of nuclear power plant operating on the combined cycle with the oil powered plant with same cycle shows that the cost of desalination of the former is about 19\% lower than the latter using the RO. Water production cost of RO coupled with nuclear power plant operating on the gas cycle (NGC) is about 32\% cheaper than RO coupled with oil powered plant operating on gas cycle (OGC).

The cost of power production is as depicted in Figure 2. Power production cost from using nuclear power plant (NSC) is about 74\% lower than oil power plant operating on the steam cycle (OSC). Using (NSC) is about 25\% cheaper than (CSC). Again power production a nuclear power plant operating on the combined cycle is about $54 \%$ lower than the corresponding oil powered plant.

The effect of interest rate on desalination cost using NSC and OSC are shown in Figures $\mathbf{3}$ and $\mathbf{4}$ respectively. The cost of water production increases steadily with interest rate. For NSC cost at $8 \%$ interest rate is about $12 \%$ higher than the cost at $5 \%$ interest rate. However, for e OSC, cost at $8 \%$ interest rate is about $7 \%$ higher than the corresponding price at $5 \%$ interest rate.

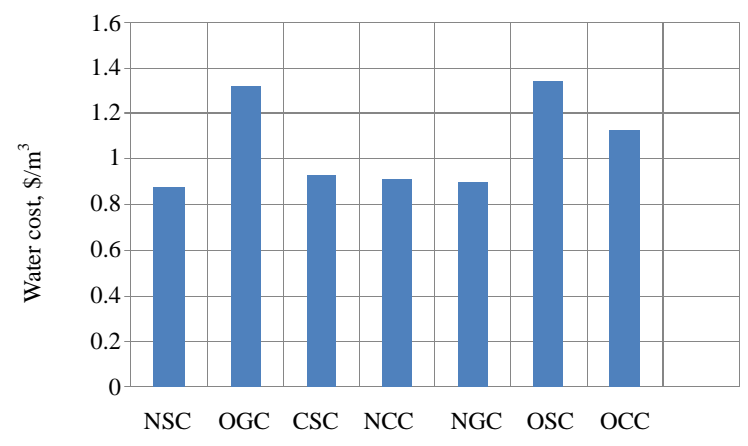

Figure 1. Water production cost from various fuel and power cycles combinations.

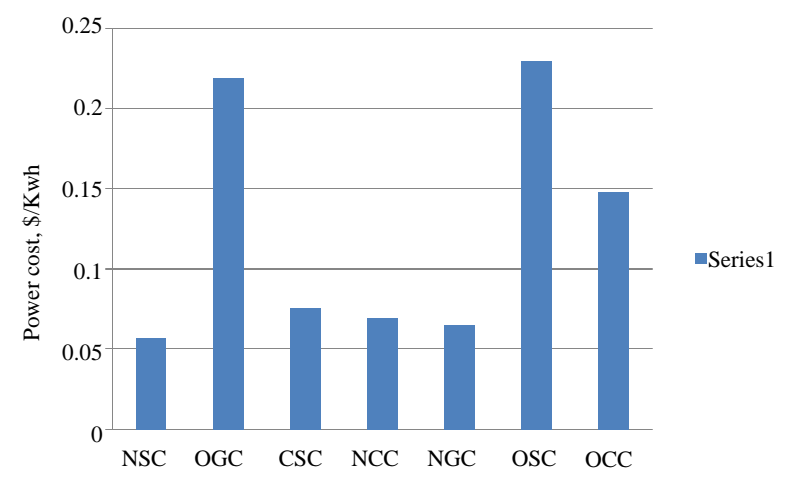

Figure 2. Power production cost from various fuel and power cycle combinations. 


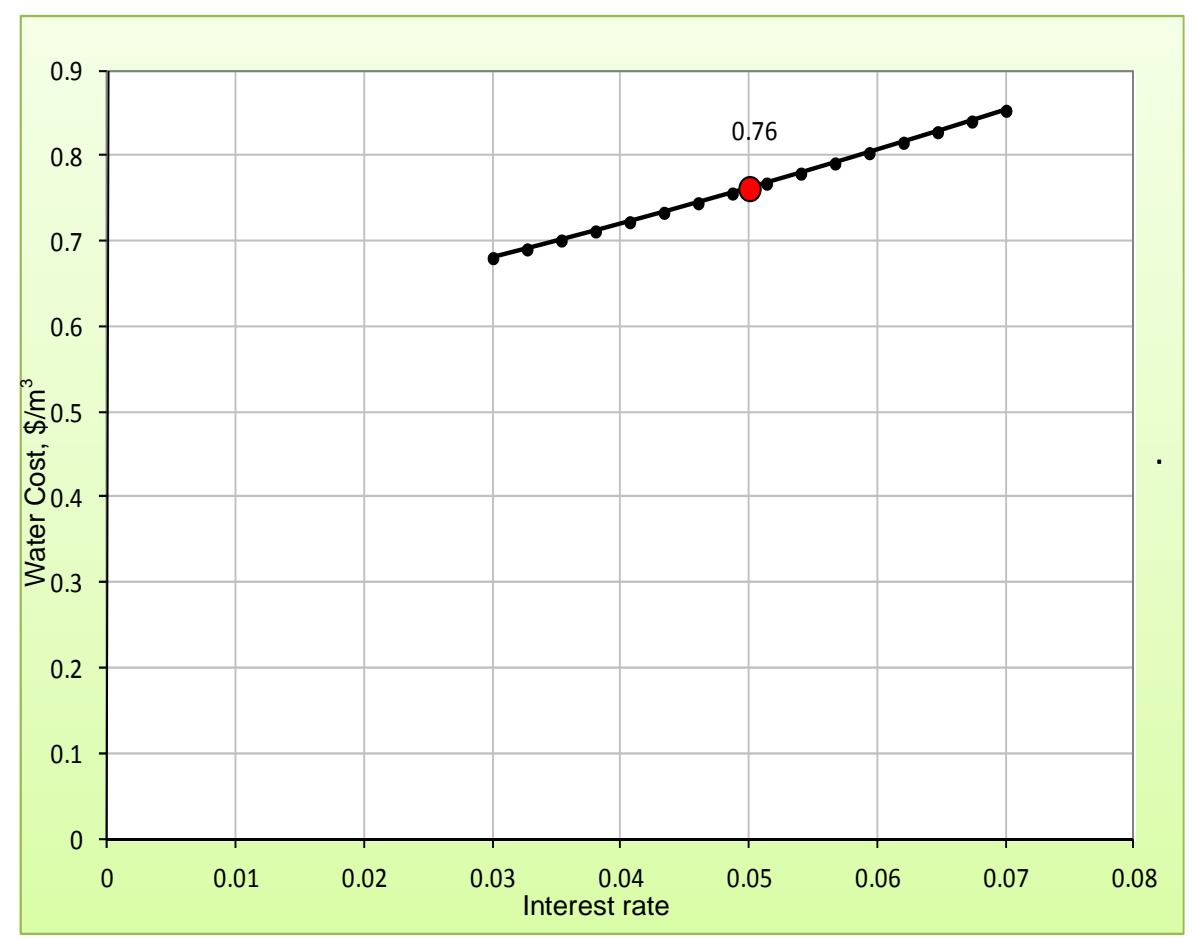

Figure 3. Effect of interest rate water production cost for NSC.

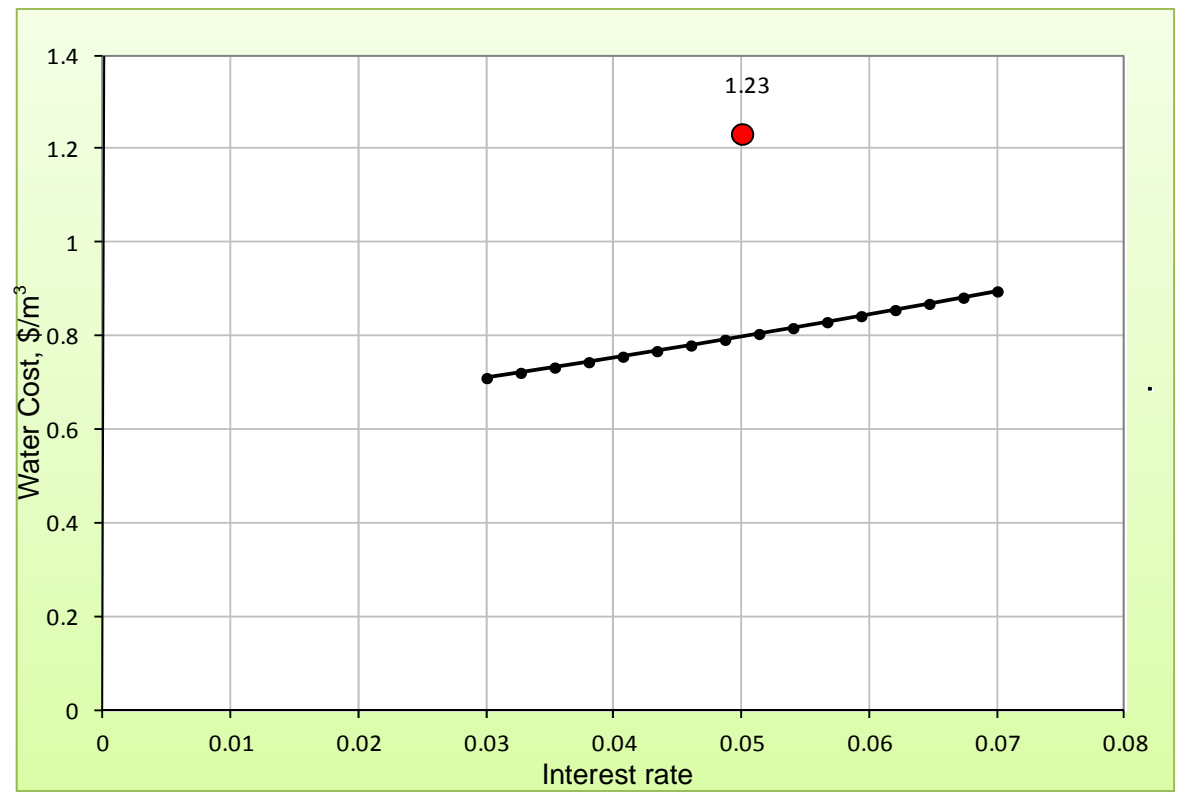

Figure 4. Effect of interest rate on water production cost for OSC.

The effect of fuel escalation on cost of water production using NSC (Figure 5) is more pronounced than corresponding costs desalination using OSC (Figure 6). The magnitudes of the prices at similar escalation rates are, however, higher for OSC than NSC.

\section{Conclusions}

Various power plant sizes are available and can offer wide range of economic specifications depending on specific site. The choice of power source and the operating power cycle coupled with desalination plants for co-generation should be carefully chosen as a possible long-term investment project. The results of the simulation and analysis indicate that:

- Co-production nuclear power plant operating on steam cycle is most economic than combined and gas cycles 


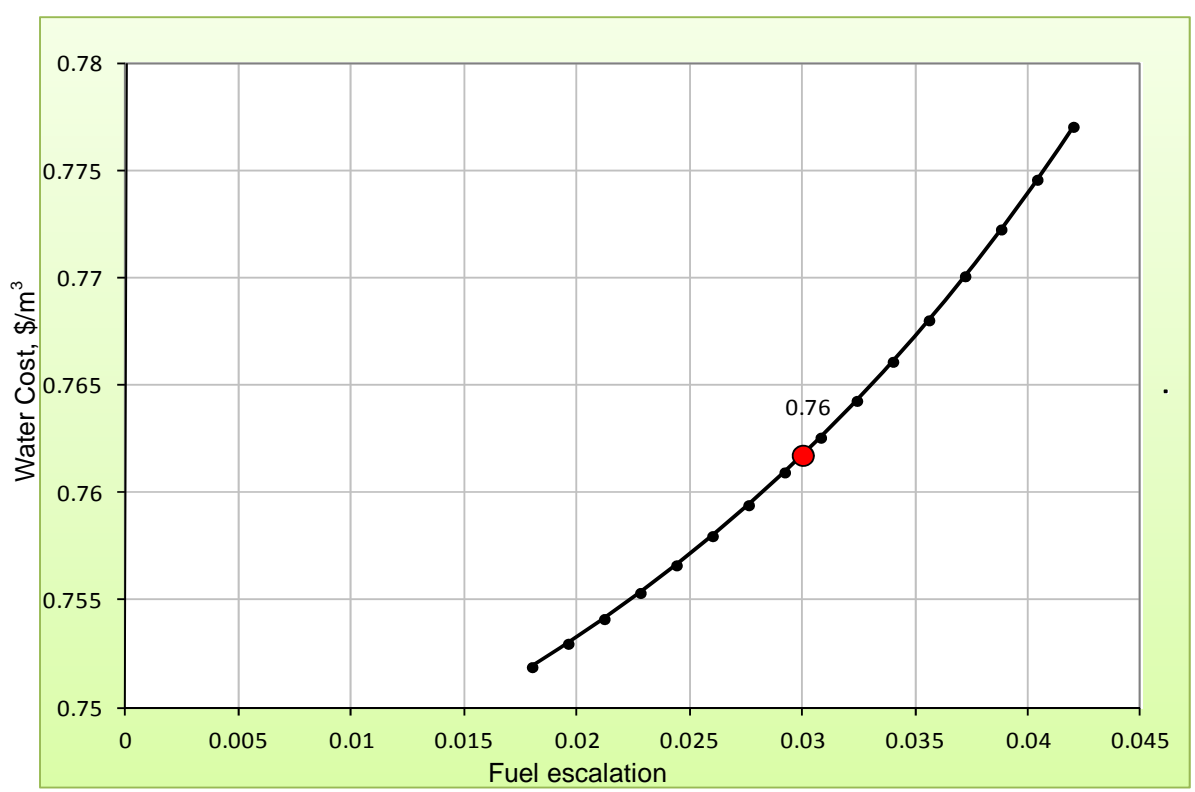

Figure 5. Effect of fuel escalation on water production cost for NSC.

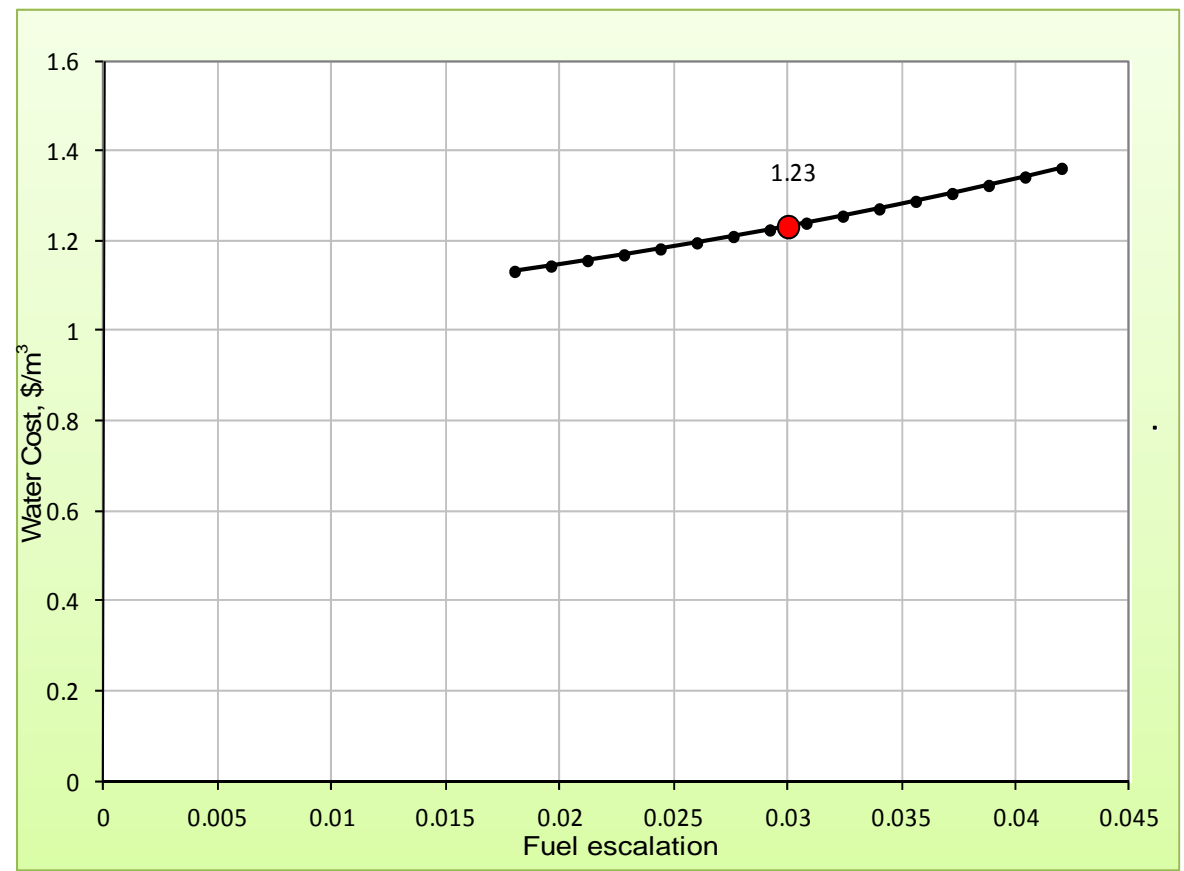

Figure 6. Effect of fuel escalation on water production cost for OSC.

- Co-production of power and portable water from nuclear power plant operating on the rankine cycle is more competitive than fossil power plant operating on rankine cycle.

- Discount rate has a greater effect on water cost especially for nuclear energy source than for conventional energy source based desalination because of the high capital cost and relatively long construction periods in NPP.

- Fuel price changes affect water price in fossil plant rather than in nuclear options.

\section{Acknowledgements}

The authors gratefully acknowledge IAEA making Software simulator DEEP available.

\section{REFERENCES}

[1] K. V. Reddy and N. Ghaffour, "Overview of the Cost of 
Desalinated Water and Costing Methodologies,” Desalination, Vol. 205, No. 1-3, 2007, pp. 340-353. doi:10.1016/j.desal.2006.03.558

[2] IAEA, "Examining the Economics of Seawater Desalination Using the DEEP Code,” International Atomic Energy Agency, Vienna, 2000, IAEA-TECDOC-1186.

[3] Befesa Desalination Developments Ghana Limited, "Environmental Impact Statement on Proposed Seawater Reverse Osmosis Desalination Plant at Nungua, Accra,” 2011.

[4] S. Nisan and S. Dardour, "Economic Evaluation of Nuclear Desalination Systems,” Desalination, Vol. 205, No. 1, 2007, pp. 231-242. doi:10.1016/j.desal.2006.05.014

[5] O. K. Bouhelal, R. Merrouch and D. Zejli, "Costs Investigation of Coupling an RO Desalination System with a Combined Cycle Power Plant, Using DEEP Code,” Desalination, Vol. 165, 2004, pp. 251-257. doi:10.1016/j.desal.2004.06.029

[6] Y. M. El-Sayed, "Thermo-Economics of Seawater Desalination System,” Proceeding IDA World Congress, Madrid, Vol. 4, 1997, pp. 149-166.
[7] A. Valero, C. Torres and F. Lerch, "Structural Theory and Thermo-Economic Diagnosis-Part III: Intrinsic and Induced Malfunctions," Proceedings of the ECOS'99 Conference (ASME), Tokyo, 1999, pp. 35-41.

[8] A. Valero, L. Correas and L. Serra, "On-Line Thermo Economic Diagnosis of Thermal Power Plants," Thermodynamic Optimization of Complex Energy Systems, Vol. 69, 1999, pp. 117-136. doi:10.1007/978-94-011-4685-2 8

[9] “Thermodynamics and Optimization of Complex Energy Systems,” Kluwer Academic Publishers, Dordrecht, 1999, pp. 117-136.

[10] F. J. U. Marcuello, “Thermo-Economic Analysis and Simulation of a Combined Power and Desalination Plant,” Ph.D. Thesis, University of Zaragoza, Zaragoza, 2000, pp. 123408.

[11] IAEA, "Thermodynamic and Economic Evaluation of CoGeneration Plants for Electricity and Potable Water,” International Atomic Energy Agency, Vienna, 1997, IAEATEC-DOC 942. 


\section{List of Acronyms}

NSC: Nuclear power plant operating on steam cycle

OSC: Oil power plant operating on steam cycle

CSC: Coal power plant operating on steam cycle

NGC: Nuclear power plant operating on gas cycle

NCC: Nuclear power plant operating on combined cycle

OGC: Oil power plant operating on gas cycle

OCC: Oil power plant operating on combined cycle

\section{Appendix I Summary of Cost Results for NSC}

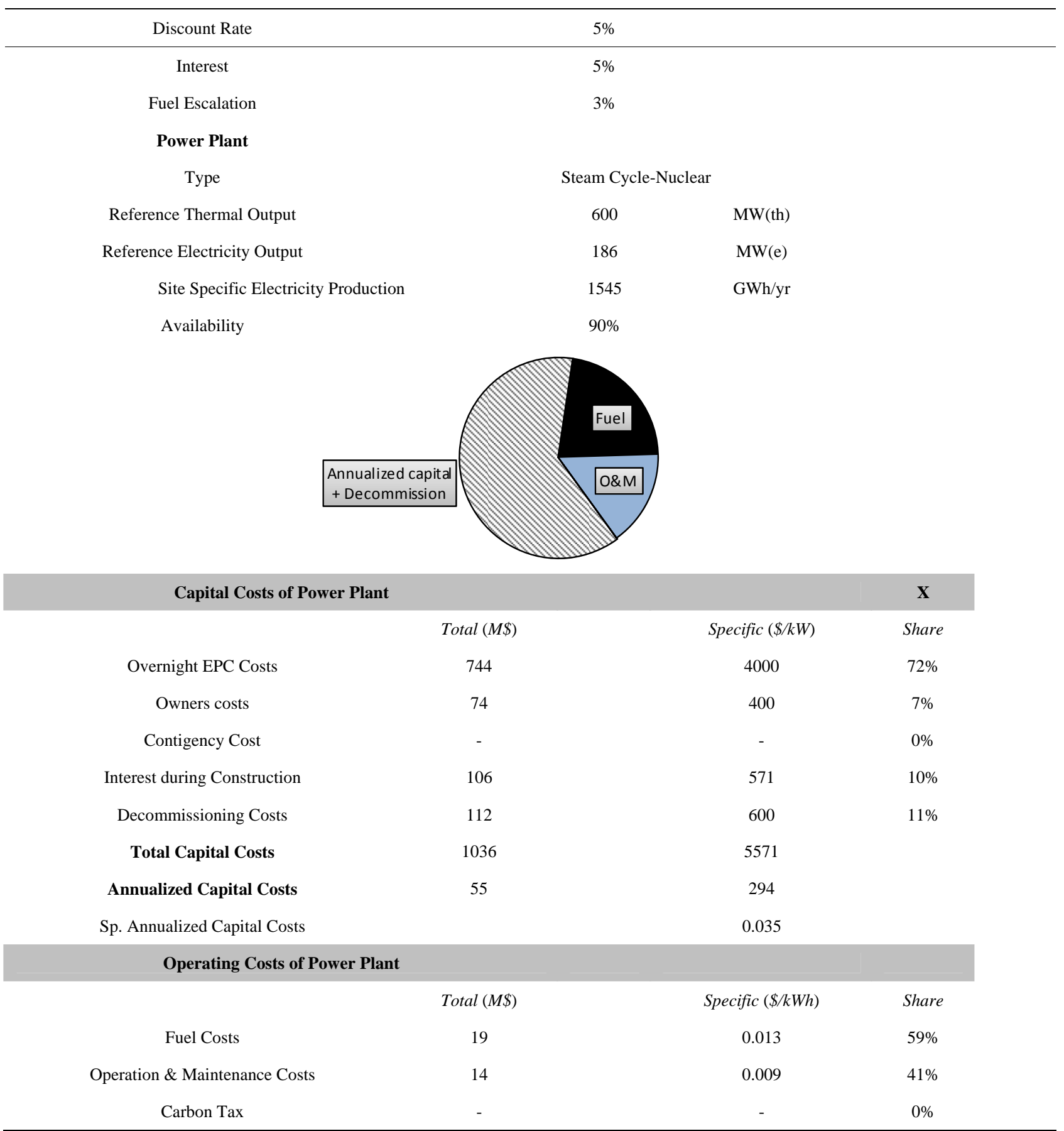


Continued

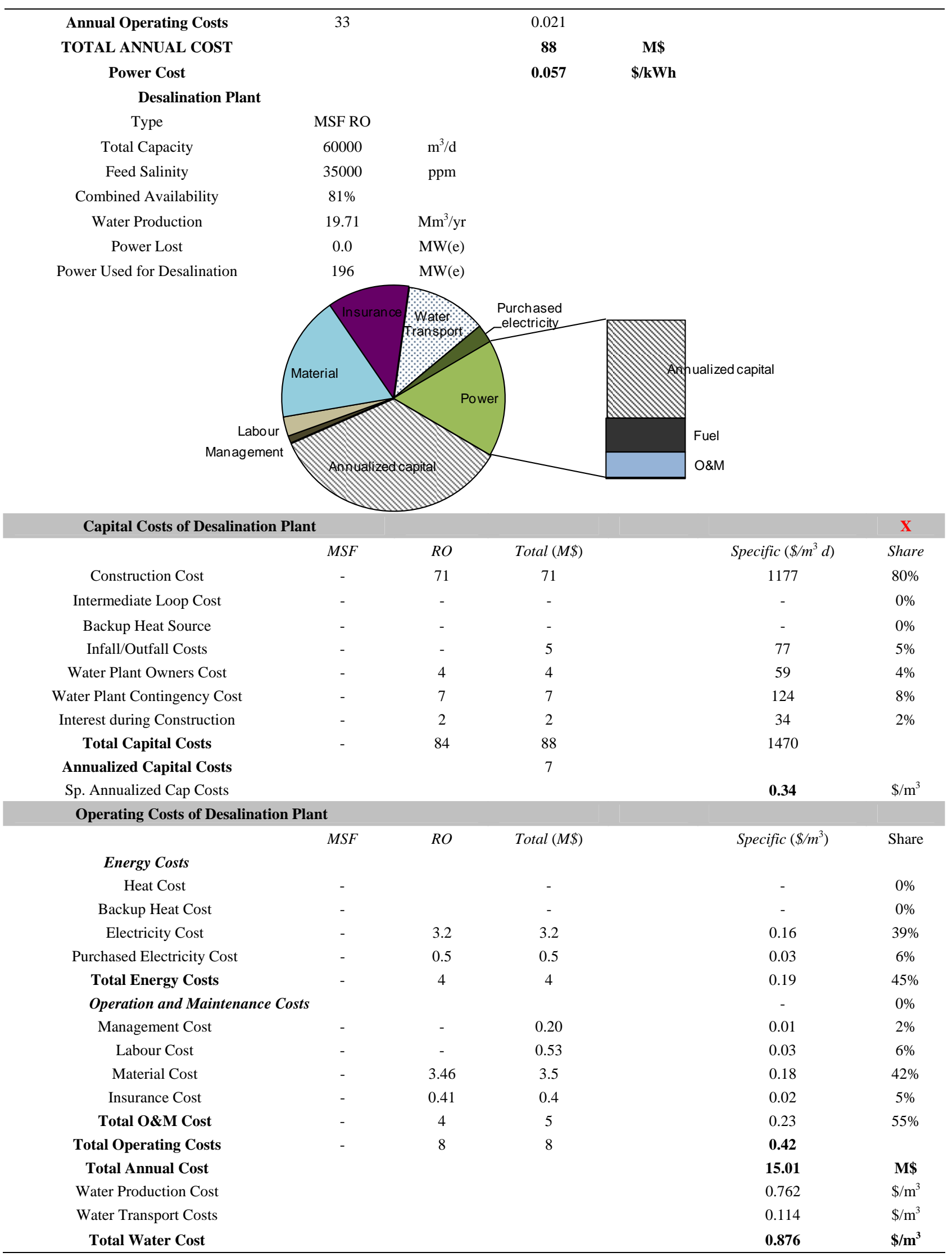




\section{Appendix II Summary of Cost Results for OSC}

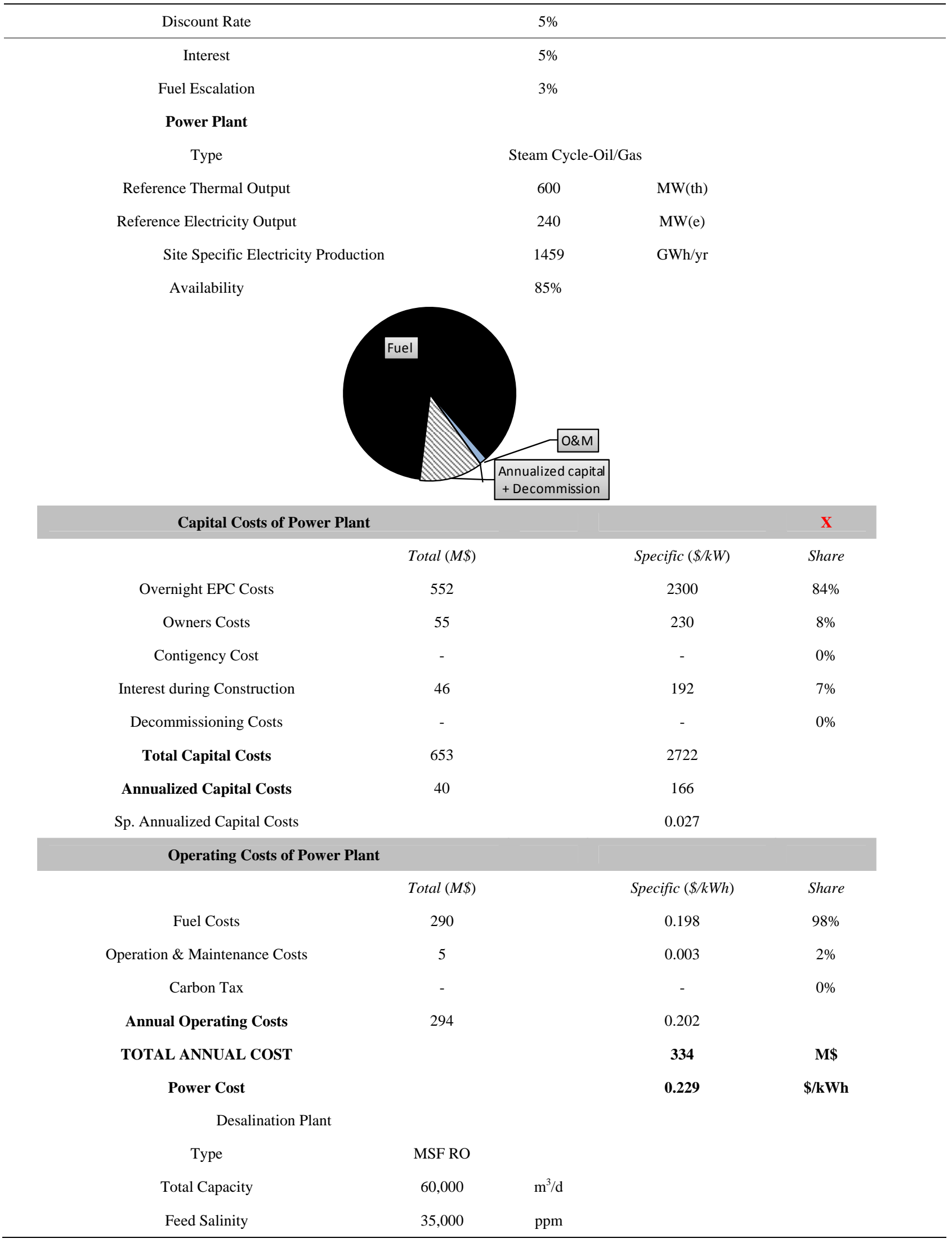




\section{Continued}

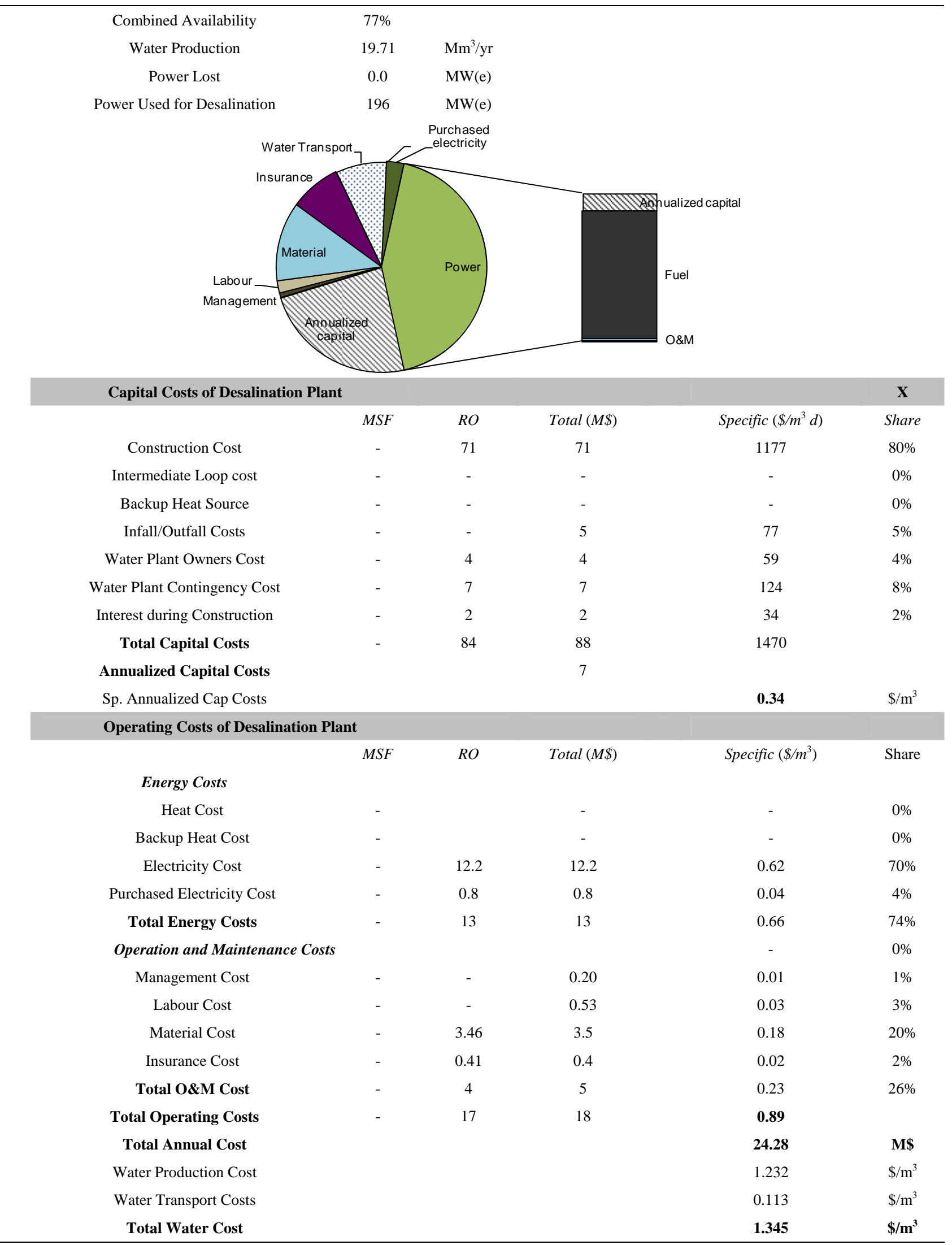

